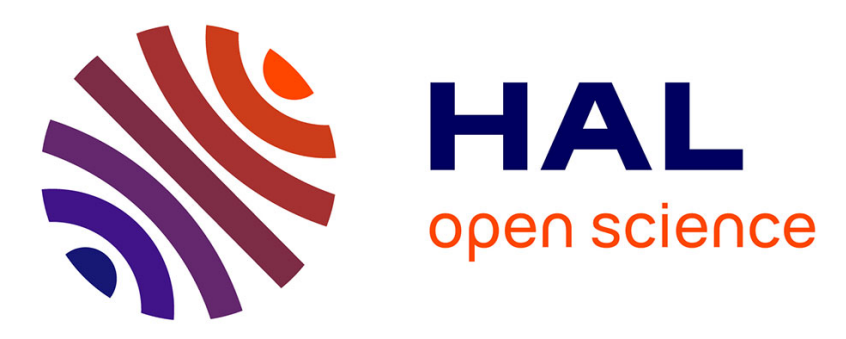

\title{
Magnetic Structure of Hexagonal Ferrites Studied by Mössbauer Spectroscopy
}

\author{
M. Nejezchleba, Z. Simsa, K. Zaveta
}

\section{To cite this version:}

M. Nejezchleba, Z. Simsa, K. Zaveta. Magnetic Structure of Hexagonal Ferrites Studied by Mössbauer Spectroscopy. Journal de Physique IV Proceedings, 1997, 07 (C1), pp.C1-345-C1-346. 10.1051/jp4:19971139 . jpa-00254782

\section{HAL Id: jpa-00254782 https://hal.science/jpa-00254782}

Submitted on 1 Jan 1997

HAL is a multi-disciplinary open access archive for the deposit and dissemination of scientific research documents, whether they are published or not. The documents may come from teaching and research institutions in France or abroad, or from public or private research centers.
L'archive ouverte pluridisciplinaire HAL, est destinée au dépôt et à la diffusion de documents scientifiques de niveau recherche, publiés ou non, émanant des établissements d'enseignement et de recherche français ou étrangers, des laboratoires publics ou privés. 


\title{
Magnetic Structure of Hexagonal Ferrites Studied by Mössbauer Spectroscopy
}

\author{
M. Nejezchleba, Z. ŠimŠa* and K. Záv̌̌ta*
}

\author{
Joint Laboratory of Mössbauer Spectroscopy, KFNT-MFF UK, V Hole§ovickách 2, 18000 Praha 8, \\ Czech Republic \\ * Institute of Physics, Academy of Sciences of the Czech Republic, Cukrovarnická 10, 16200 Praha 6, \\ Czech Republic
}

\begin{abstract}
Hexagonal Ba-ferrites of $\mathrm{M}$-type ( $\left.\mathrm{BaFe}_{12} \mathrm{O}_{19}\right)$ and $\mathrm{W}$-type $\left(\mathrm{BaMe}^{2+}{ }_{2} \mathrm{Fe}^{3+}{ }_{16} \mathrm{O}_{27}, \mathrm{Me}\right.$-divalent cation) are promising materials for perpendicular magnetic recording. For this purpose it is desirable that their high uniaxial anisotropy be adjustable according to the specific requirements. Substitution of $\mathrm{Co}^{2+}$ for $\mathrm{Fe}^{2+/ 3+}$ cations usually decreases the magnitude of the uniaxial anisotropy and may be used to this end.

In this work the influence of $\mathrm{Co}^{2+}$ content on the details of magnetic structure of Ba-hexaferrites is studied.

Móssbauer spectra of ${ }^{53} \mathrm{Fe}$ in single crystals of $\mathrm{BaFe}_{12-2 x} \mathrm{Co}^{2+}{ }_{x} \mathrm{Ti}^{4+}{ }_{x} \mathrm{O}_{19}$ and $\mathrm{Ba}\left(\mathrm{Fe}_{2-x} \mathrm{Co}_{x}\right)^{2+} \mathrm{Fe}_{16} \mathrm{O}_{27}$ were measured at $293 \mathrm{~K}$. The dependence of the canting of magnetic moments on the concentration of $\mathrm{Co}_{0}$ was determined from the relative intensities of Mossbauer lines in the Zeeman nuclear multiplet and compared with the results deduced from the magnetic measurements.
\end{abstract}

\section{INTRODUCTION}

Hexagonal Ba-ferrites of $\mathrm{M}$ - and $\mathrm{W}$-types are two from several magnetic iron oxides based on a hcp structure of oxygen divalent ions. The magnetic structure of both of these types is then given by strong superexchange interactions between magnetic cations via oxygens. Here lies the origin of the uniaxial anisotropy found with these types of Ba-hexaferrite. These hexaferrites may prove suitable for perpendicular recording. One of the requirements is, however, a special range of the anisotropy field values. Replacing of iron ions by some other ones with different single-ion anisotropy contribution might lead to lower anisotropy. The present experience, however, shows that some more complex changes in moment arrangement in the magnetic structure. When $\mathrm{Co}^{2+}$ is used as a substitution, the magnetic moments in various magnetic sublattices tend to cant from the hexagonal $c$-axis direction. The main aim of this work is to study in details of the magnetic structure of the mentioned structures by two different methods: magnetization measurements and Mössbauer spectroscopy.

\section{EXPERIMENTAL}

\subsection{Characterisation of samples}

Two series of single crystals barium hexaferrites of $\mathrm{M}$ - and $\mathrm{W}$-types with various content of $\mathrm{Co}$ have been used for magnetic measurements. (For denotation see Tab. 1). Both series

\begin{tabular}{|c|c|}
\hline Sample & $\begin{array}{c}\text { Co } \\
\text { content }\end{array}$ \\
\hline M0 & 0 \\
\hline M1 & 0.11 \\
\hline M4 & 0.35 \\
\hline M8 & 0.78 \\
\hline W0 & 0 \\
\hline W1 & 1 \\
\hline W2 & 2 \\
\hline
\end{tabular}

Tab. 1: Denotation of samples

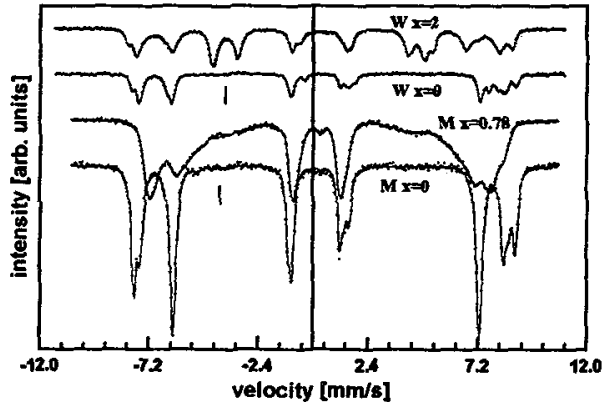

Fig. 1: Mossbauer spectra of selected samples of $\mathrm{M}$ - and W-series; the tags (1) entitle parts of spectra reflect the changes of the magnetic structure

\subsection{Magnetic measurements}

A SQUID magnetometer has been used for measuring the W-series of samples and a vibrated sample magnetometer for the $M$-series samples at room temperature. Both series have been measured along the hard magnetization direction. Values of anisotropy field have been estimated from the measured magnetization curves without consideration of higher anisotropy constant contributions. The canting 
angle of magnetization $\theta_{M}$, with respect to the c-axis, was estimated from the magnitude of the component of $M$ into the hard direction at moderately low fields that should be equal to $M_{s} \cdot \sin \theta_{M}$.

\subsection{Mössbauer spectroscopy}

${ }^{57}$ Fe transmission Mössbauer spectroscopy in constant acceleration mode has been used. All the spectra have been measured at room temperature. The samples have been oriented with the hexagonal axes parallel to the $\gamma$-ray propagation direction.

For decomposing the spectra, sextets with the Voight line shapes have been used according to particular ferrite sublattices. The angles $\theta$ between magnetic moments on given ions of iron and propagation of a $\gamma-$ ray have been calculated from ratios of intensities in sextets by wellknown expression (see e.g. [1]):

$$
\vartheta=\arcsin \sqrt{\frac{2 R_{23}}{4+R_{23}}},
$$

where $R_{23}=I_{2,5} / I_{3,4}$ are ratios of intensities of the 2 nd and 5 th line to the $3 \mathrm{rd}$ and 4 th ones in given sextets. The $R_{23}$ value has been fitted by considering the same value for all sextets, except the cases mentioned below.

\section{RESULTS AND CONCLUSIONS}
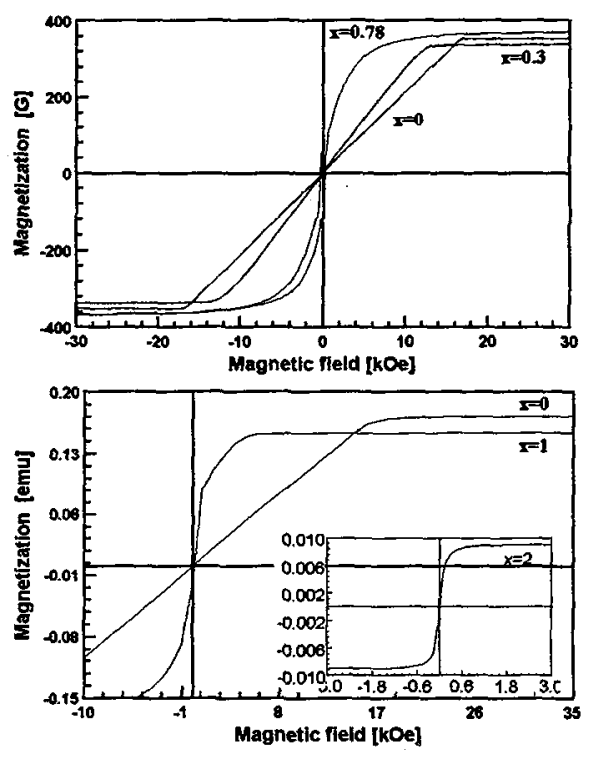

Fig. 2: Magnetization curves for M- (top) and Wseries (bottom)

The selected spectra together with their fits and the magnetization curves are shown in figs. 1 and 2 , respectively. The final results are summarized in Tab. 2. Since the samples were of very similar shape, we did not correct values of anisotropy field for the dernagnetization field. It is seen that in both structures the Co substitution results in a decrease of the anisotropy field. From the experimental data, in particular from the Mössbauer spectra, it follows that with gradual substitution of Co for Fe in both $\mathrm{M}$ - and $\mathrm{W}$-type hexagonal ferrites the magnetization in the sublattices makes an angle with the c-axis. The values of the canting angle $\theta$ given in the Tab. 2 correspond to an effective angle common to all sublattices. The detailed analysis of the Mössbauer spectra of the samples M5-8 indicates that the canting is not homogeneous and that its value is higher for the sublattice where $\mathrm{Co}$ is substituted [2]. The agreement between the conclusions about the changes of magnetization arrangement with $\mathrm{Co}$ substitutions derived from the magnetization measurements and Mössbauer spectra is found satisfactory.

\section{Acknowledgement}

The help of Dr. M. Maryško with magnetic measurements is gratefully acknowledged.

\section{References}

[1] Gonser U.: Mössbauer Spectroscopy I., Springer-Verlag, BerlinHeidelberg-New York, 1975, p. 29

[2] Lego S.: Ph.D. Thesis, Faculty of Mathematics and Physics, Charles University, Prague, 1995

\begin{tabular}{|c|c|c|c|c|}
\hline $\begin{array}{c}\text { Denot. } \\
\text { of sam. }\end{array}$ & $\begin{array}{c}\text { Cont. of } \\
\mathrm{Co}\end{array}$ & $\begin{array}{c}\mathrm{H}_{\mathrm{A}} \\
{[\mathrm{kOe}]}\end{array}$ & $\begin{array}{c}\theta_{\mathrm{M}} \\
{\left[{ }^{\circ}\right]}\end{array}$ & $\begin{array}{c}\theta \\
{\left[{ }^{\circ}\right]}\end{array}$ \\
\hline \hline $\mathrm{M} 0$ & 0 & 16.9 & 0 & 0 \\
\hline $\mathrm{M} 1$ & 0.11 & - & - & 11 \\
\hline $\mathrm{M} 5$ & 0.35 & 13.7 & $\sim 0$ & 13 \\
\hline $\mathrm{M} 8$ & 0.78 & 5.6 & 18 & 20 \\
\hline $\mathrm{W} 0$ & 0 & 18 & 0 & 0 \\
\hline $\mathrm{W} 1$ & 1 & 6.0 & 35 & 23 \\
\hline $\mathrm{W} 2$ & 2 & $0.9(5)$ & 60 & 64 \\
\hline
\end{tabular}

Tab. 2: Table of final results; $H_{\mathrm{A}}$.. anisotropy field, $\theta_{M}$ and $\theta$.. deviation of magnetization from $c$ axes derived from magnetization curves and Mössbauer spectra, resp. 